\title{
Professional Stress of the National Police of Ukraine: Psychological Dimension
}

\author{
Zoriana Kisil * [0000-0003-1405-4547], Viacheslav Blikhar [0000-0001-7545-9009], \\ Halyna Katolyk [0000-0002-2169-0018] \\ Lviv State University of Internal Affairs, Lviv, Ukraine \\ *zoriana-kisil@ukr.net
}

Stress is the flavor and taste of life, it can only be avoided by someone who does not do anything...

G. Selie

\begin{abstract}
The article consolidates the theoretical and methodological analysis of stress determinants that affect employees of the National Police of Ukraine in the procedure of performance of their official duties; includes methodological substantiation of methods and main tasks of experimental research of stress resistance of policemen. The main determinants of stress resistance formation in the National Police of Ukraine are underlined; the structural components of personality and the influence of individual psychological properties of personality as a subject of activity on the ways of constructing behavioral strategies of stress management in stressful conditions of activity are characterized. An understanding of the relationship between stress resistance and individual and psychological characteristics is analyzed. It was found that the problem of stressful experience is extremely important, and the ability to overcome it and cope with it is transformed into essential problem. It is noted that the lack of psycho-emotional training of police officers leads to poor quality of operational tasks, sometimes determine injuries and even can lead to their death.
\end{abstract}

Keywords: employees of the National Police of Ukraine, professional stress, psychological determinants of professional stress, overcoming strategies, special conditions of activity, extreme situations, stress factors.

\section{INTRODUCTION}

The transformation processes that take place in our state require the effective functioning of law enforcement agencies as the effective system. The reform of the law enforcement system puts forward a number of requirements for the new generation of police officers, educational conditions for their professional training, which will promote the formation of professional competencies in the National Police and actualize personal potential of policemen. An important role in these processes is devoted to the modern system of psychological training of law enforcement officers, which is positioned as system activities, related with psychological support of professional development of future police officers and personal psychological support at all stages of their professional growth.

The professional activity of police officers is sometimes carried out under very difficult conditions, such as: instability of the political and economic situation in Ukraine, extreme occupational distress, conditions of risk and danger, constant lack of time, extremely high level of personal responsibility for the consequences of professional activity. The opinion of scientists related with the problem of police officers distress underlines that the dilemma of experiencing stressful situations is very relevant today, and practical skills and abilities to overcome stress are mostly transformed into a behavioral dilemma [1-9]. Thus, the lack of proper psychological and emotional training of employees of the National Police of Ukraine, sometimes leads to inefficient implementation of operational and service tasks, injuries, and sometimes even can cause officers death.

Thus, the introduction of a unit of psychological training and support of employees of the National Police of Ukraine in the training system will create the most optimal conditions for personal and professional development, the ability to effectively perform 
professional tasks in ever-changing conditions, will lead to integration of skills of mental self-regulation and reflection, forecasting skills in everyday official activities and in emergency situations [10-12]. All these circumstances determine the relevance and need to study the determinants of stress in the professional activities of employees of the National Police of Ukraine.

Scientific researches of following scientists is devoted to the problematic issues of psychological training and psychological support of the National Police: O. Asmolov, O. Bandurka, V. Barko, O. Bondarenko, I. Vashchenko, E. Yevdokimova, I. Klimenko, N. Ligun, S. Lebedeva I. Okhrimenko, R. Pavelkina, O. Timchenko, V. Osyodlo, V. Ostapovych, O. Synyavska, V. Stasiuk, V. Shveda and others. are:

In particular, the main areas of conducted researches

- analysis of the specifics of the professional activities of police officers and conduction of the empirical identification of it's intensity;

- analysis of the features of manifestations of professional stress among law enforcement officers in stressful and risky situations and its psychological consequences;

- conduction of a practical study of psychological factors in the development of stress in law enforcement officers activities.

In view of the above, the purpose of this scientific investigation is to study the psychological determinants of stress in law enforcement officers of Ukraine activities.

\section{RESEARCH METHODS METHODOLOGIES}

AND

In order to perform the tasks of our scientific research following methods were used: empirical - served to conduct empirical research; theoretical and methodological - used to analyze the scientific achievements of scientists in this field; the dialectical method facilitated the consideration of stress in dynamics and provided an opportunity to outline approaches to its prevention; systemic - served to identify determinants of stress in employees of the National Police of Ukraine; formal-logical served to position the psychosomatic status of law enforcement; the experimental method and the method of active modeling were used in the process of conducting an empirical study of the impact of stress factors on the professional activities of police officers.

\section{DESCRIPTION OF PSYCHODIAGNOSTIC RESEARCH TOOLS}

In order to diagnose the determinants of stress in the professional activities of law enforcement officers [13-
15], authors used proven research methods, namely: Holmes-Reich scale of stress resistance and social adaptation (SLS), Boston stress test and "Comprehensive Assessment of Stress" (Y. Shcherbatykh), such questionnaires as "Occupational Stress" (K. Wyman); "Inventory of Stress Symptoms" (T. Ivanchenko); "Differentiated Assessment of States of Reduced Working Capacity" (G. Leonova, B. Velychkovsky); number of other methods, namely: "Losses and Gains of Personal Resources" (N. Vodopyanova, M. Stein), "Coping Strategies in Stressful Situations" (S. Norman, D. Endler, D. James, M. Parker (adaptation by T. Kryukova), author's questionnaire - to study the needs of police officers in anti-stress programs.

The experiment, that was held under the procedure of current research was attended by 167 students of the Center for Postgraduate Education, Distance Learning of Lviv State University of Internal Affairs (applicants for higher education (distance learning)), who represented MD NP in Lviv region- 50 people, Vinnytsia region - 20, Volyn region - 15, Zacarpathian region - 12, IvanoFrankivsk region - 27, Chernivtsi region - 19, Ternopil region - 24 people). Division by gender criteria: 138 males, 29 - females.

\section{RESEARCH RESULTS AND DISCUSSION}

Despite the antiquity of permanent attempts to study the phenomenon of "stress", among scientists there are still differences in attitude toward this problem. Today, most scientists, discussing the determinants of stress, pay considerable attention to the main features of professional activity [8]. A number of psychologists note that the stress that arises in the individual in the process of professional duties should be analyzed as a characterological type of stress (A. Furnham, 1992) occupational stress (A. Ross, E. Altmeier, 1999) [4].

Apriori, the work of police officers is always accompanied by stress factors determined with a high level of complexity of tasks alongside with a high level of personal responsibility. Among a number of stress factors that have a negative impact on the psychological and emotional state of police officers, scientists distinguish the following procedures namely: the release of hostages; confrontation with an armed offender; injury, obtained during the official duties; constant interaction with representatives of the criminal subculture; high degree of personal responsibility for the decisions; high level of stress and risk of functions performed; use of physical coercion or firearm in professional activities s and more [3, 6, 8].

Modern studies of occupational stress in the National Police of Ukraine functioning suggest that phenomenologically and in terms of the nature of the mechanism of regulation "professional stress of police officers" is a specific type of stress, which should be 
positioned as a multidimensional phenomenon of physiological and psychological response of the officers on the complicated functioning sphere [6].

A thorough analysis of scientific research on the nature of psychological and occupational stress makes it appropriate to consider the mechanisms of stress dynamics in the National Police of Ukraine. In particular, at the stage of macro-analysis of "professional stress"in police officers activity, it is possible to obtain a systematic description of the determinants of risks in operational and service activities in terms of causal relationships. Research at the stage of transitional mediation of stress will help to take into account the individual and psychological characteristics of the police and his own practical experience in the prevention of stressful situations. The level of micro-analysis, which positions the actual psychological mechanisms of adaptation of a particular police officer to stressful circumstances, will help to predict the quality and effectiveness of the implementation of real operational and service tasks.

A thorough study of scientific research in this area allows us to conclude that the structure of the model of "professional stress" of Ukrainian police officers is correctly divided in three main blocks, namely: external and internal stress determinants; physiological and actually psychological manifestations of occupational stress.

\section{ANALYSIS AND INTERPRETATION OF THE RESULTS OF EMPIRICAL RESEARCH}

The study of the impact and consequences of the actual psychological determinants of stress in the police of Ukraine during this research has been carried out in two stages. Thus, at the first stage we carried out a theoretical and methodological analysis of the existing problem; the second stage involved an empirical study, which contributed to the analysis of the peculiarities of the "professional stress" in the police of Ukraine and the establishment of psychological factors of their occurrence.

At the first stage, in order to analyze the degree of "professional stress" and its symptoms, to interpret the emotional, behavioral, physiological states in the police of Ukraine, we used a valid method of "Comprehensive stress assessment" (Y. Shcherbatykh). As a result of the survey conducted by Y. Shcherbatykh $41 \%$ of respondents had moderate stress, 23\% had "obvious" stress, $2 \%$ had severe stress, and 34\% had no stress (Figure 1).

To position the prevailing indicators and characteristics of "professional stress" and to underline the characteristic features of the response of employees of the National Police of Ukraine to those factors we conducted a factor analysis. Thus, according to the results of factor analysis, we have identified three potential factors that significantly affect the personality of the National Police of Ukraine officers and their reaction to "occupational stress"(Figure 2).

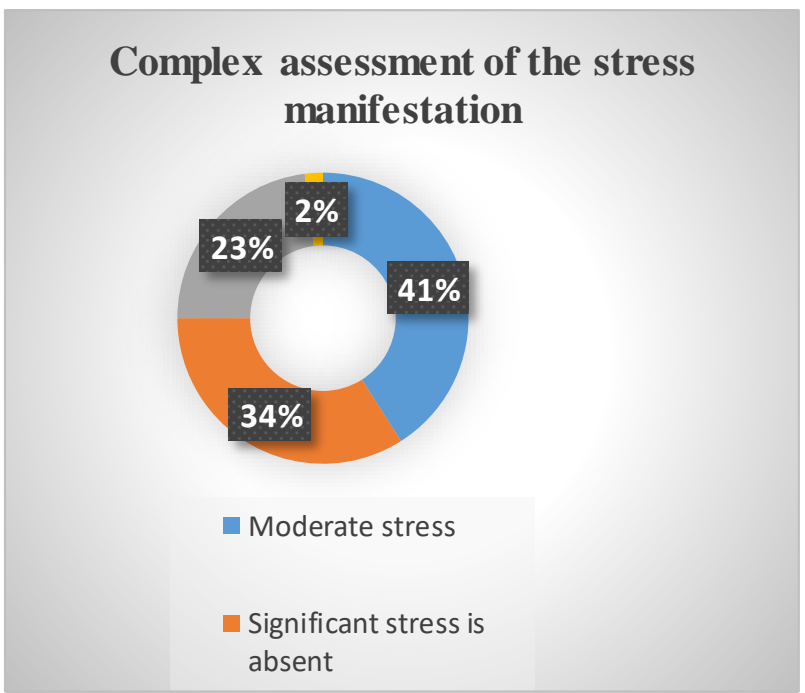

Figure 1 Distribution of respondents according to the method of Y. Shcherbatykh

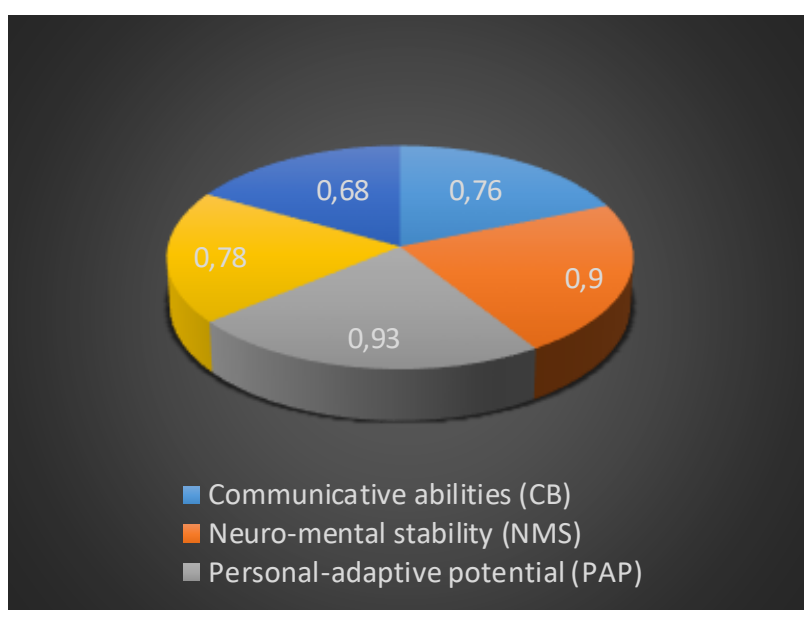

Figure 2 Picture of the first factor "Anxiety-adaptive individual differences in response"

The psychological quintessence of the first factor is actually that the dynamics of the development of "professional stress" in police officers is influenced by the following determinants, namely: personal adaptive index (0.93), neuropsychological stability (0.90), anxiety $(0,78)$, communicative abilities $(0.76)$ and ethical norms (0.68). The high degree of the factor "personal adaptive potential" indicates that respondents have a high level of motivational focus on achieving significant goals in the performance of professional activities, experience in adapting to existing changes in social and political life, satisfaction with the chosen realm of activity and others. The high level of neuro-psychological stability indicates that the officers of National Police of Ukraine have logic and purposefulness in carrying out their professional 
duties. The influence of the anxiety factor is represented with the fact that the professional activity of police officers is always accompanied by a high degree of complexity of their tasks and a high level of responsibility for their results. The indicator "communicative abilities" testifies to the ability of police officers to apply the following basic functions of contact in everyday professional activities, namely: communicative, interactive, perceptual. Undoubtedly, the self-assessment of the officers of National Police of Ukraine of their own actions only within the legal field should correspond to their personal internal imperative. Strict observance of the laws and their implementation in everyday professional activities are most fundamental for police officers, as those are the basis of their own moral responsibility to both the community and personal conscience. Only the norms of the current legislation understood by a police officer can be acquired in the sphere of their own values and thus gain the importance of moral norms.

The second factor "Peculiarities of individual differences in stress", obtained as a result of the factor analysis, provided an opportunity to identify determinants of the algorithm of development of "occupational stress" in police officers activities (Figure 3).

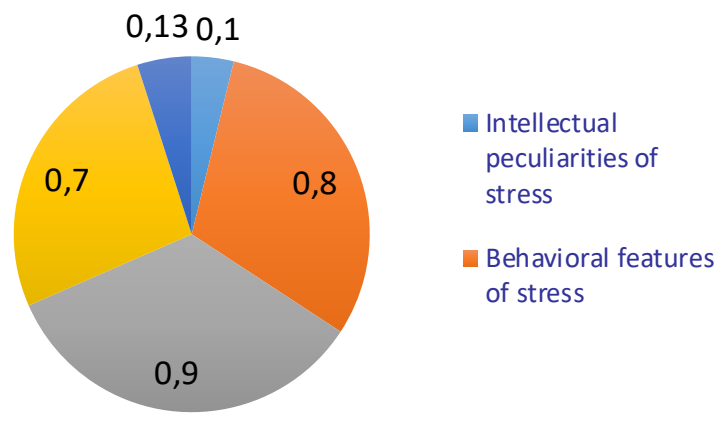

Figure 3 The image of the second factor "Features of individual differences in the manifestation of stress"

The high level of physiological stress $(0.71)$ is caused by the uniqueness of the professional activities of police officers, as their official activities are constantly filled with both physical and mental pressure. During the emergence of risky situations, under the influence of certain difficulties in the performance of professional duties, because the information uncertainty, or during the abnormal situations, officers of the National Police of Ukraine always experience emotional stress (0.84). The need to choose a coping strategy during stressful situations often causes information stress of police officers (0.86). As practical experience shows, everyday manifestations of stress in the performance of official duties by the officers of the National Police of Ukraine can have both activating and disorganizing results which leads to a general decrease in the equivalence of mental activity and further - to the appearance of signs of stress in police officer's behavior (0.86).

The third factor "Peculiarities of personal productivity" is composed from two diagnostic criteria (Figure 4).

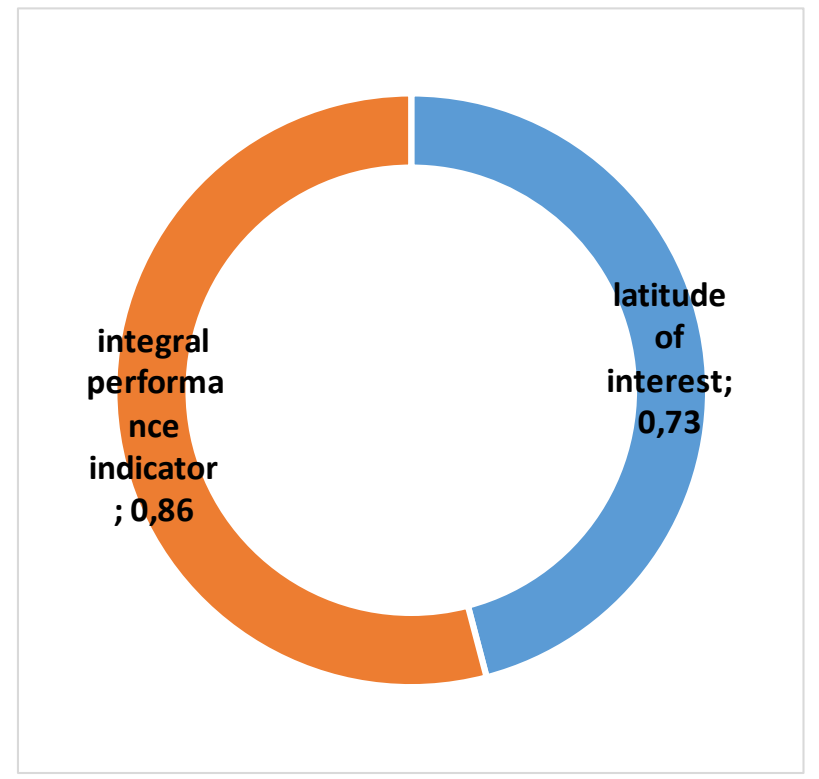

Figure 4 Picture of the third factor "Features of personal productivity"

The psychological meaning of the factor "Spectrum of interests" $(0.73)$ is actually about the course of stress in police officers who are always influenced by general intellectual development, range of interests, the implementation of the modern paradigm - lifelong learning.

Using the method of expert assessments of success in the official activities of law enforcement bodies, we found that the greatest impact on the professional success of respondents have: "Professionalism" - $5.7 \pm 0.06$ points; "Intelligence" - $4.9 \pm 0.08$ points; "Leadership" $5.4 \pm 0.07$ points; "Self-control" - $5.4 \pm 0.10$ points (Table 1).

The method of "Self-assessment of stress resistance" (S. Cowhen, G. Willianson) contributed to the possibility to conclude that the degree of correlation, indicated in police officers can be underlined both in terms of relationships and the weight of correlation coefficients (0.72).

The ascertaining stage of the scientific research was aimed at finding out the basic needs of police officers in training programs designed to prevent and overcome stress. During the survey, $75.9 \%$ of respondents said that there were no anti-stress programs in their departments, 
which indicates a lack of attention to the most important problem of today, namely: providing practical assistance in preventing and overcoming "occupational stress". $69.2 \%$ of police officers stated that there was a priority need to introduce a psychological unit within the framework of police training, designed to provide law enforcement officers with both theoretical and practical skills to prevent and overcome stress.

Table 1. Characteristics of factors that determine the success of professional activities of officers of the National Police of Ukraine

\begin{tabular}{|c|c|c|c|c|}
\hline 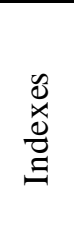 & 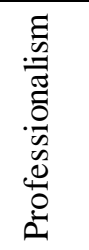 & $\begin{array}{l}\stackrel{\vec{U}}{\vec{E}} \\
\stackrel{\vec{\Xi}}{\Xi}\end{array}$ & 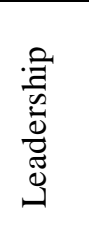 & 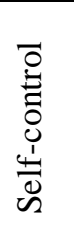 \\
\hline $\mathrm{M}$ & 5,7 & 4,9 & 5,4 & 5,4 \\
\hline$\sigma$ & 0,6 & 0,9 & 0,7 & 1,0 \\
\hline $\mathrm{m} \pm$ & 0,06 & 0,08 & $\begin{array}{l}0,07 \\
\end{array}$ & 0,10 \\
\hline
\end{tabular}

The authors research suggests that the prevention and overcoming of "professional stress" in the daily service of employees of the National Police of Ukraine requires professional psychological conditions, namely: 1) mastering knowledge about the nature and determinants of "professional stress"; 2) mastering the psychological methods of manifestation of "professional stress"; 3) research of the psychological and organizational mechanism of prevention and overcoming of "professional stress".

\section{CONCLUSIONS AND PROSPECTS OF FURTHER RESEARCH}

1. Occurrence of professional stress in police officers activity is determined by a variety of factors that are caused by specific conditions of their professional activity.

2. The official activity of police officers is always conditioned by a number of stress factors, namely: release of hostages; confrontation with an armed offender; injury or injury in the course of official duties; constant interaction with representatives of the criminal subculture; high degree of personal responsibility for the decisions made; high level of stress and risk of functions

\section{REFERENCES}

[1] Bano, B. (2011), "Job stress among police personnel", International Conference on Economics and Finance Research (IPEDR), vol. 4, pp. 290-293. performed; use of physical coercion or firearms in professional activities and more.

3 . The expediency of applying three main approaches in the study of occupational stress is argued: 1) since the motive for its occurrence is the mismatch of requests of the professional environment and personal resources of the police, it is important to establish an imbalance in the system "personality of the police - his work environment" and develop an algorithm; 2) since occupational stress arises due to a high degree of subjective assessment of the existing conflict situation, then it is necessary to correctly formulate the vector of tolerant and balanced behavior, designed to overcome all problems in communication; 3) because stress causes deregulation of the mechanisms of professional activity of police officers, and thus to the overestimation of "overestimation" of personal potentials, accumulation of permanent effects that cause chronic pathological changes in personality structure, there is an urgent need to introduce anti-stress training programs in police training.

4. The model of "professional stress" of Ukrainian police consists of three main blocks: external stress determinants; internal stress determinants; physiological and actually psychological manifestations of occupational stress.

5. The conducted empirical research helped to determine the specific features of "professional stress" in police officers and to establish the weight of a number of determinants, namely: personal adaptive index, nervous and mental stability, anxiety, communication skills, moral imperative. In the course of empirical research we found that high data of physiological and emotional stress are a consequence of the specifics of the professional activities of police officers.

6 . The main professional psychological principles of anti-stress training of police officers are: 1) mastering knowledge about the essence and determinants of the formation of "professional stress"; 2) mastering psychological methods of manifestation of "professional stress"; 3) research of the psychological and organizational mechanism of prevention and overcoming of "professional stress".

7. A comprehensive approach to preventing and overcoming the phenomenon of "professional stress" in police officers involves the constant implementation of psychological support with the use of interactive antistress programs.

[2] Ostapovich, V. Barko, V. Okhrimenko, I., and et al. (2020), 'Psychological Profile of Successful Criminal Police Officer", International Journal of Applied Exercise Physiology, vol. 9 (3), pp. 120133, available at: http://www.ijaep.com/index.php /IJAE/article/view/755 
[3] Shane, J. (2010), "Organizational stressors and police performance", Journal of Criminal Justice, vol. 38, pp. 807-818.

[4] Wood, J.D., Watson, A.C., and Barber, C. (2021), "What can we expect of police in the face of deficient mental health systems? Qualitative insights from Chicago police officers", Journal of Psychiatric and Mental Health Nursing, vol. 28 (1), pp. 28-42.

[5] Tsai, L.C.F. Nolasco, C.A.R. and Vaughn, M.S. (2018), "Modelling job stress among police officers: the interplay of work environment, counselling support, and family discussion with coworkers", Police Practice and Research, vol. 19(3), pp. 253-269.

[6] Yevdokimova, O. and Okhrimenko, I. (2020), 'Coping Strategies for Overcoming Stress in Atypical Situations, Broad Research in Artificial Intelligence and Neuroscience (BRAIN), vol. 11 (2 Sup 1), pp. 56-63. DOI: $10.18662 /$ Brain/11.2sup1/94

[7] Fedorenko, O. Dotsenko, V. Okhrimenko, I. Radchenko, K. and Gorbenko, D. (2020), ,Coping Behavior of Criminal Police Officers at Different Stages of Professional Activity", Broad Research in Artificial Intelligence and Neuroscience (BRAIN), vol. $11(2), \quad$ pp. 124-146. DOI: $10.18662 / B R A I N / 11.2 / 78$

[8] Kisil, ZR (2016), Legal and psychological principles of prevention of professional deformation of law enforcement officers: monograph, Lviv State University of Internal Affairs, Lviv, Ukraina.

[9] Osyodlo, V. (2013), "Personal factors in overcoming stressful situations in special conditions", Problems of extreme and crisis psychology, vip. 14 (1), pp. 242-252.

[10] Korystin, Oleksandr and Svyrydiuk, Nataliia (2021), "Formation of security competences in law enforcement activities", Nauka i Pravookhorona, vol. 1 (51), pp. 191-198, DOI: 10.36486/np.2021.1(51).20

[11] Korystin, Oleksandr and Svyrydiuk, Nataliia (2021), "Activities of Illegal Weapons Criminal Component of Hybrid Threats", Proceedings of the International Conference on Economics, Law and Education Research (ELER 2021), Series: Advances in Economics, Business and Management Research, vol.170, 22 March, pp. 8691, DOI: 10.2991/aebmr.k.210320.016

[12] Korystin, O.Y. Katamadze, G.S. Nekrasov, V.A. Mel'nyk, V.I. and etc. (2021), Fiscal Security of Ukraine - Threats, Risks, Vulnerabilities: Strategic vision, Vidavnichij Dim, Gelvetika, LLC, Kherson, Ukraine

[13] Javier González Marqués and Carlos Pelta (2013), "PSICO-A: A Computational System for Learning Psychology", IJMECS, vol. 5, no. 10, pp.18. DOI: $10.5815 /$ ijmecs.2013.10.0

[14] Prashant M. Dolia (2013), "Evaluation: The New Philosophical Roles \& Psychological Means", IJMECS, vol. 5, no. 7, pp. 34-40. DOI: 10.5815/ijmecs.2013.07.04

[15] Mritunjay Rai, R.K.Yadav, Agha A. Husain, Tanmoy Maity and Dileep K. Yadav( 2018), "Extraction of Facial Features for Detection of Human Emotions under Noisy Condition", IJEM, vol. $8, \quad$ no. $5, \quad$ pp. 49-62. DOI: 10.5815/ijem.2018.05.05 